\title{
Streptozotocin-induced Diabetes Causes Crucial Morphological Changes in Abdominal Motoneurons and Muscles of Rats
}

\author{
Naomi Oshiro ${ }^{1}$, Ken Muramatsu ${ }^{2}$, Toru Tamaki ${ }^{3}$, Masatoshi Niwa ${ }^{{ }^{*}}$ \\ ${ }^{1}$ Department of Occupational Therapy, Kyorin University, Tokyo, Japan \\ ${ }^{2}$ Department of Physical Therapy, Kyorin University, Tokyo, Japan \\ ${ }^{3}$ Department of Physical Therapy, Health Science University, Yamanashi, Japan
}

\section{Abstract}

Background: Diabetic neuropathy (DN) is a major complication of diabetes. Although it is wellestablished that DN targets sensory and autonomic nerves, little is known about its influence on motor disorders.

Methods: This study investigated morphological alterations inabdominal (Abd) motoneurons and muscles of experimental type I diabetic rats. Alterations in the number and size of Abd motoneurons were studied using retrograde labeling techniques in diabetic rats 6 or 14 weeks after injection of streptozotocin (diabetic group). Age-matched control animals were labeled at 6 or 14 weeks after saline injection (control group). Further, the thicknesses of the external oblique, internal oblique, transversus abdominis (TA), and rectus abdominis muscles were similarly examined and the cross-sectional area of the TA myocytes was measured.

Results: The number and mean size of cell bodies significantly decreased in Abd motoneurons in the diabetic group compared with the control group $(\mathrm{P}<0.05)$. As diabetes progressed, there was a clear decrease in the number and mean motoneuron size $(\mathrm{P}<0.05)$. In the diabetic group, the thickness of Abd muscles was reduced, as was the cross-sectional area of the TA myocytes $(\mathrm{P}<0.05)$. Moreover, there was a clear decrease in muscle thickness and in the cross-sectional area of the myocytes $(\mathrm{P}<0.05)$.

Conclusion: We suggest that hyperglycemia induceda reduction in the number and size of Abd motoneurons and atrophy of Abd muscles at 6 and 14 weeks after induction of diabetes by streptozotocin. Therefore, Abd muscular disorders caused by hyperglycemia may relate to a wide range of disorders, such as those involved with expiratory, defecation function, and trunk movement.

\section{Publication History:}

Received: April 05, 2018

Accepted: June 01, 2018

Published: June 04, 2018

\section{Keywords:}

Trunk motoneurons, Trunk muscles, Degeneration, Diabetes, Diabetic neuropathy

\section{Abbreviations:}

Abd: Abdominal, BF: biceps femoris, DN: diabetic neuropathy, EO: external oblique, IO: internal oblique, L1: 1st lumbar spinal cord, MG: medial gastrocnemius, RA: rectus abdominis, SD: standard deviation, STZ: streptozotocin, T13: 13th thoracic spinal cord, TA: transversus abdominis, 6WD: 6 weeks after induction of diabetes, 14WD: 14 weeks after induction of diabetes, 6WC: 6 weeks after saline injection, 14WC: 14 weeks after saline injection.

\section{Introduction}

Diabetic neuropathy (DN) is symmetric and duration dependent, and involves sensory loss, pain, and distal weakness in the early stage of diabetes [1-3]. However, in the later stage, muscle weakness spreads through proximal areas, including ankles, knees, and hips, whereas "stocking and glove" sensory losses remain restricted to distal regions $[4,5]$. These weaknesses also correlate highly with the severity of $\mathrm{DN}[5,6]$.However, we recentlyrevealed a significant decrease in the number of labeled gamma motoneurons [7] and a loss of labeled alpha motoneuronsinmedial gastrocnemius (MG) muscles, followed by a later loss of labeled gamma motoneurons in MG muscles using retrograde labeling technique [8]. Our finding will help in elucidatingthe mechanism of motor disturbance of diabetic patient. However, to date, there is no information available on how diabetes affects the motoneurons other than hindlimb motoneurons.

Abdominal (Abd) muscles consist of the external oblique (EO), internal oblique (IO), transversus abdominis (TA), and rectus abdominis (RA), which are innervated by motoneurons located in the ventral horn of the lower thoracic and upper lumbar spinal cord $[9,10]$. Abd muscles play an important role in posture and walking [11-13]; vomiting [14]; and respiration, particularly the control of expiration [15-17]; and excretion movements, such as defecation and urination $[15,18]$. Therefore, functional decline in Abd muscles due to DNis expected and included in various dysfunctions. However, there is no information about how diabetes affects Abd motoneurons and muscles, although Abd muscles play such an important role.

We used streptozotocin (STZ) to induce experimental type 1diabetes in rats and examined anatomical alterations in motoneurons in Abd motor nuclei by using retrograde-labeling techniques. In addition, we performed morphological examination of Abd muscles.

"Corresponding Author: Prof. Masatoshi Niwa, Department of Occupational Therapy, Kyorin University, Tokyo, Japan, 5-4-1 Shimorenjaku, Mitaka, Tokyo 181-8612, Japan, Tel: +81-422-47-8000, Fax:+81-422-47-8077; E-mail: mt-niwa@ks.kyorin-u.ac.jp

Citation: Niwa M, Oshiro N, Muramatsu K, Tamaki T (2018) Streptozotocininduced Diabetes Causes Crucial Morphological Changes in Abdominal Motoneurons and Muscles of Rats. Int J Phys Ther Rehab 4: 143. doi: https://doi. org/10.15344/2455-7498/2018/143

Copyright: @ 2018 Niwa et al. This is an open-access article distributed under the terms of the Creative Commons Attribution License, which permits unrestricted use, distribution, and reproduction in any medium, provided the original author and source are credited. 
Citation: Niwa M, Oshiro N, Muramatsu K, Tamaki T (2018) Streptozotocin-induced Diabetes Causes Crucial Morphological Changes in Abdominal Motoneurons and Muscles of Rats. Int J Phys Ther Rehab 4: 143. doi: https://doi.org/10.15344/2455-7498/2018/143

Page 2 of 8

\section{Materials \& Methods}

All animal experiments were performed in accordance with the National Institutes of Health guide for the care and use of Laboratory animals (NIH Publication No. 8023, revised 1978). All the experimental procedures were approved by the Animal Ethics Committee of Kyorin University.

Forty-two 13-week-old male Wistar rats (purchased from Sankyo Labo Service Corporation, Inc., Tokyo, Japan) were used in this experiment. Type 1 diabetes was induced by administration of STZ $(100 \mathrm{mg} / \mathrm{kg}$ in saline; i.p.) in 22 animals. Plasma glucose was determined to confirm the diabetic status. Twenty age-matched control animals were injected with saline only. All animals were housed in plastic cages with a flat bottom covered by soft bedding material. Food and tap water were provided ad libitum. Animals were maintained in a temperature-controlled room with a 12-hour light/ dark cycle.

\section{Measurements of motoneurons}

At 4 weeks or 12 weeks after STZ or saline injection, the diabetic and age-matched control animals were used for motoneurons labeling. All animals were anesthetized with $4 \%$ halothane at the induction of anesthesia and maintained with inhalation halothane at $1 \%$. Rectal temperature was maintained at $37-38^{\circ} \mathrm{C}$ by using a heating pad. Under aseptic conditions, the ventral branch of the 13th thoracic spinal cord (T13)nerve and the first lumbar spinal cord (L1) nerve were dissected from Abd muscles, and the central cut ends of T13 and L1 nerves were dipped for 1 hour in a small polyethylene tube containing $10 \%$ 3kDadextran-fluorescein (D3306, Molecular Probes, Eugene, OR, USA) or 10\% 3kDdextran-Texas Red (D3328, Molecular Probes, Eugene, OR, USA) dissolved in saline (Figure 1). The tubes were placed on absorbent cotton to prevent the dextran-fluorescein and dextran-Texas Red solutions from spreading to surrounding tissue. After 1 hourof exposure to the solutions, the nerves were washed with normal saline and enveloped with gelatin, again, to prevent dextran solutions from spreading to the surrounding tissues. Antibiotics were administered and the incision was closed.
After a survival period of 2 weeks, the animals were re-anesthetized with pentobarbital (35 mg/kg; i.p.) and perfused transcardially with $500-1000 \mathrm{~mL}$ of normal saline containing heparin sodium, followed by $4 \%$ paraformaldehyde in $0.1 \mathrm{M}$ phosphate buffer at $4^{\circ} \mathrm{C}$. The $\mathrm{T} 8$ to L2 portion of the spinal cord was removed and placed in cold fixative (4\% paraformaldehyde) for 24 hours. Next, the 8th thoracic spinal segment through the 2 nd lumbar spinal segment was sectioned serially on a vibratome (longitudinal $80-\mu \mathrm{m}$-thick sections). These sections were mounted on glass slides and examined through fluorescence microscopy. Microscope images were photographed by using a digital camera (BX-50, OLYMPUS, Tokyo, Japan). The numbers of motoneurons and diameters of the soma in the digital images were measured using Image J (NIH, Bethesda, MD, USA). We calculated the average soma diameter (half of the sum of the maximum and minimum diameters of the ovals) in Abd cell bodies.

\section{Measurements of Muscle Thickness and Myocytes}

At 6 weeks or 14 weeks after STZ or saline injection, the diabetic and age-matched control animals were used for measurements of muscles. To examine the degree of muscle atrophy of Abd muscles, histological analysis was conducted on EO, IO, TA, and RA muscles. We used Abd muscles innervated by the Th13 and $\mathrm{L} 1$ nerves. The Th13 nerve innervates the upper portion of Abd muscles containing EO, IO, TA, and RA muscles, and the L1 nerve innervates the lower portion of Abd muscles containing EO, IO, and TA muscles (Figure 1).

The animals were anesthetized by pentobarbital (35 mg/kg; i.p.) and euthanized by an overdose of pentobarbital $(50 \mathrm{mg} / \mathrm{kg}$; i.p.), and the Abd muscles were removed. Three muscle samples were collected along the Th13 and L1 nerves (Figure 1). A transverse section of each frozen portion was cut at $10 \mu \mathrm{m}$ thickness. For the histological analysis, sections were stained with hematoxylin-eosin. Every muscle thickness perfour muscle layers (EO, IO, TA, and RA) were measured at three points for every $1 \mathrm{~mm}$, and those means were used for analysis. We also measured the fiber area because the TA could be cut from the belly of the muscle perpendicularly. We measured the mean crosssectional area of 50 muscle cells and counted the nuclei of the muscle cells.

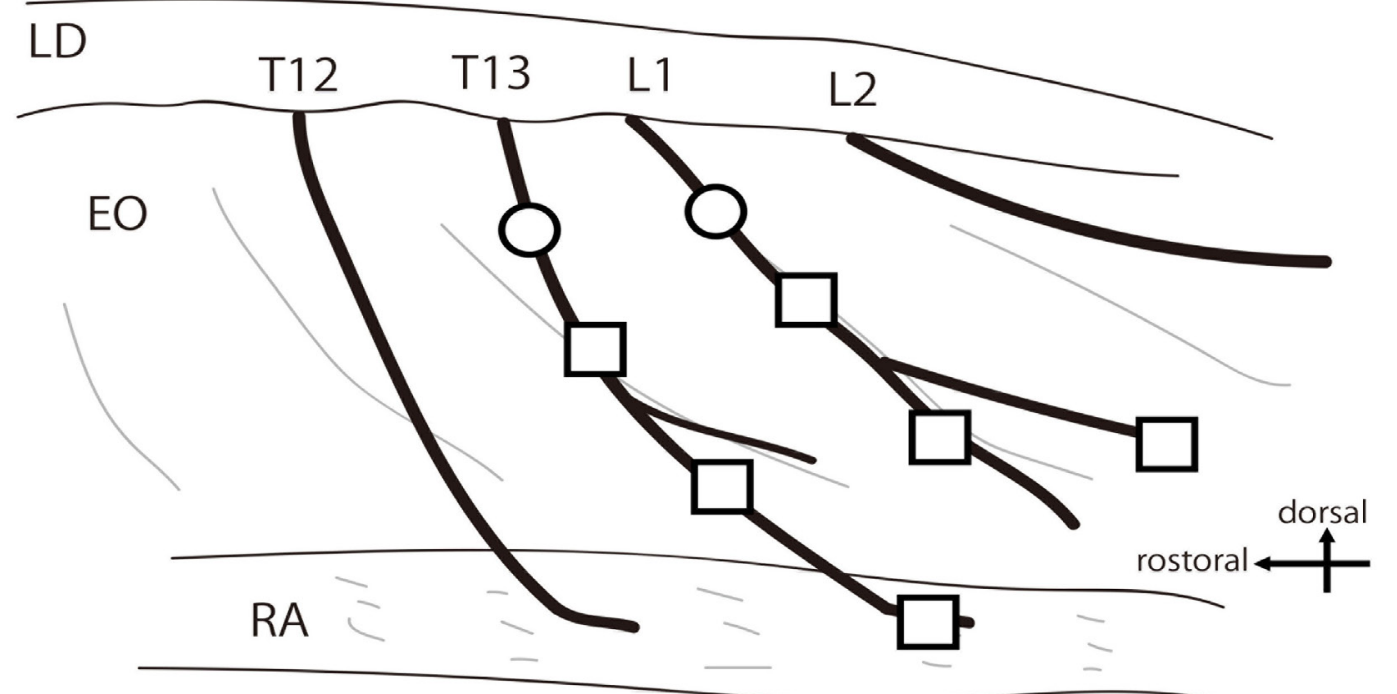

Figure 1. Schematic drawing of Abd muscles and their multisegmental innervation.

L; lumbar nerve, T; thoracic nerve, EO; M. obliquus abdominis externus, LD; M. lattismus dorsi, RA; M. rectus abdominis, O; central cut ends of nerves dipped, $\square$; three portions along the Th13 and L1 nerves sampled. 
Citation: Niwa M, Oshiro N, Muramatsu K, Tamaki T (2018) Streptozotocin-induced Diabetes Causes Crucial Morphological Changes in Abdominal Motoneurons and Muscles of Rats. Int J Phys Ther Rehab 4: 143. doi: https://doi.org/10.15344/2455-7498/2018/143

Page 4 of 8

\section{Data analysis}

Significance differences were evaluated by using independent $\mathrm{t}$-tests using SPSS software (version 23, IBM, Armonk, USA). Differences of $\mathrm{P}<0.05$ were considered statistically significant.

\section{Results}

\section{Measurements of Abd Motoneurons}

Both diabetic animals ( 6 weeks after induction of diabetes; 6WD, $\mathrm{n}=5$, and 14 weeks after induction of diabetes; $14 \mathrm{WD}, \mathrm{n}=5)$ and control animals (6 weeks after saline injection; $6 \mathrm{WC}, \mathrm{n}=5$, and 14 weeks after saline injection; $14 \mathrm{WC}, \mathrm{n}=5)$ were used for analysis (Table 1).

As shown in Figure 2, all the retrogradely labeled motoneurons were clearly identifiable by their cell bodies and dendrites and were located in the ventral horn of the spinal cord. Table 1 shows the total number and the average soma diameters of the Abd motoneurons. There was a decrease in the total number of Abd motoneurons in the diabetic group (78.1\% in T13 and $66.8 \%$ in L1 of $6 \mathrm{WD}, 81.4 \%$ in $\mathrm{T} 13$ and $72 \%$ in $\mathrm{L} 1$ of $14 \mathrm{WD})$. The total number of Abd motoneurons in L1significantly reduced in diabetic animals compared to control animals.

Figure 3 shows a frequency histogram of the average soma diameters of Abd motoneurons in each experimental group. The distributions of Abd motoneurons were unimodal. Some large motoneurons appeared to be missing in all histograms of the diabetic animals. Figure 4 shows the retrograde-labeled motoneurons arranged in a longitudinal cell column. Abd motoneurons were found largely between T13 and L1 and were intermingled within the border between T13 and L1.

\section{Measurements of Abd Muscle Thickness and Myocytes}

The diabetic animals (6WD, $\mathrm{n}=6$, and $14 \mathrm{WD}, \mathrm{n}=6$ ) and the control animals (6WC, $\mathrm{n}=4$, and $14 \mathrm{WC}, \mathrm{n}=6$ ) were used for analysis (Table 2).

To examine the degree of muscle atrophy of Abd muscles, every muscle thickness per four muscle layers (EO, IO, TA, and RA) was measured at three points for every $1 \mathrm{~mm}$ and those means were used for analysis. Macroscopically, the muscle layer in the diabetic groups appeared as a thin film as if it had no muscular tissue and there was a clear decrease in the muscle thicknesses per muscle layer in the diabetic group. There was a significant difference in Abd muscles, except RA muscle, between 6WC and 6WD animals, and in all Abd muscles between 14WC and 14WD animals (Table 2). In particular, the muscle with the greatest rate of change was TA muscle, and its thickness decreased by half in T13 and L1, respectively. Moreover, there was a significant difference in EO, IO, and TA muscles in T13, and in TA in L1 between 6WD and 14WD animals. Thus, as diabetes progressed, there was a clear decrease in the muscle thicknesses.

To examine the morphological alterations in Abd muscles, the cross-sectional area of 50 myocytes in TA muscle were measured and those means were used for analysis. Because Abd muscle was thin in the diabetic animals, it was only possible to count a maximum of 50 cells. Next the numbers of the nuclei in the myocytes were counted. The mean cross-sectional areas of TA in diabetic animals were obviously smaller than those in control animals, whereas the numbers of the myocyte nuclei were not significantly different. The mean crosssectional areas of 14WC had grown larger bigger than those of 6WC animals. When we adjusted for body weight, there was a significant difference in L1 between 6WC and 6WD animals and in both T13 and L1 between 14WC and 14WD animals (Table 2). Briefly, there was a significant difference between $6 \mathrm{WD}$ and $14 \mathrm{WD}$ animals. As diabetes progressed, a clear decrease was observed in mean cross-sectional areas (Figure 5).

\section{A}
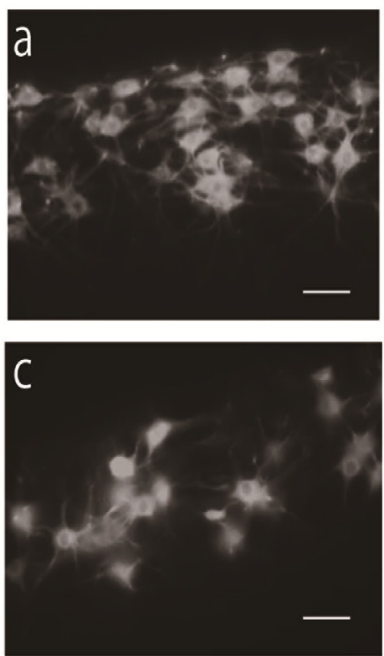
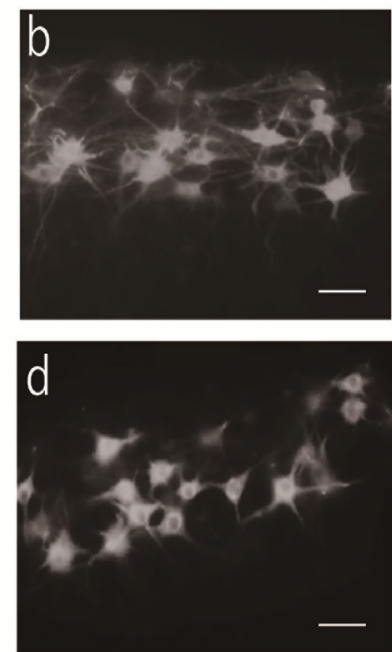

B
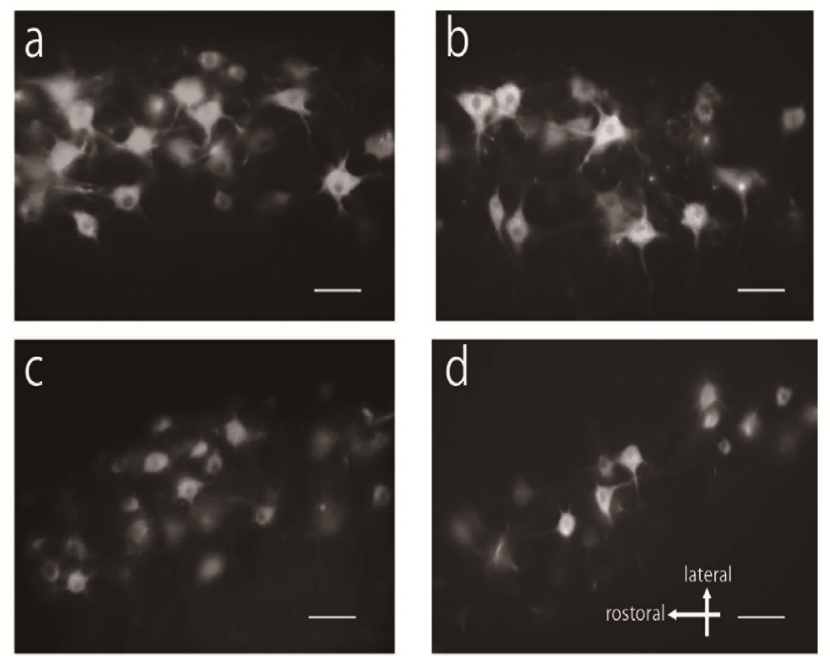

Figure 2: Representative images of retrogradely labeled Abd motoneurons in horizontal sections.

A: 6WC and 6WD, a: motoneurons of T13 in a control animal, b: motoneurons of L1 in a control animal, c: motoneurons of T13 in a diabetic animal, d: motoneurons of L1 in a diabetic animal. B: $14 \mathrm{WC}$ and $14 \mathrm{WD}$, a: motoneurons of T13 in a control animal, b: motoneurons of L1 in a control animal, c: motoneurons of T13 in a diabetic animal, d: motoneurons of L1 in a diabetic animal. 6WD: animals 6 weeks after induction of diabetes, 14WD: animals 14 weeks after induction of diabetes, 6WC: control animals, 6 weeks after injection of saline, $14 \mathrm{WC}$ : control animals, 14 weeks after injection of saline, T13: 13th thoracic spinal cord, L1: first lumbar spinal cord. Bar $=50 \mu \mathrm{m}$. 
Citation: Niwa M, Oshiro N, Muramatsu K, Tamaki T (2018) Streptozotocin-induced Diabetes Causes Crucial Morphological Changes in Abdominal Motoneurons and Muscles of Rats. Int J Phys Ther Rehab 4: 143. doi: https://doi.org/10.15344/2455-7498/2018/143

Page 3 of 8
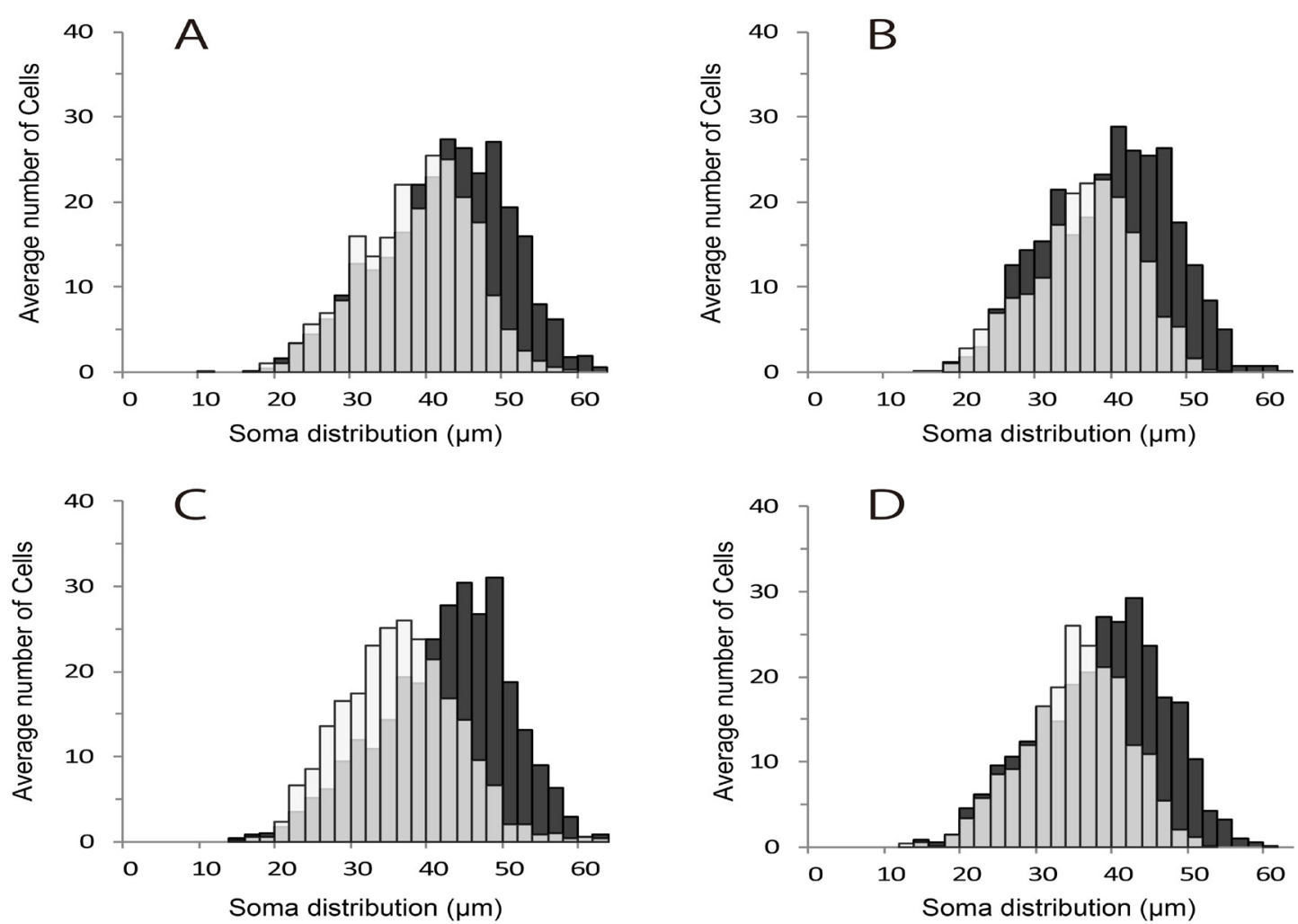

Figure 3: Distribution of the soma diameters of Abd motoneurons.

A: size distribution of T13 in 6WC and 6WD. B: size distribution of L1 in 6WC and 6WD. C: size distribution of T13 in 14WC and 14WD. D: size distribution of L1 in 14WC and 14WD. 6WD: animals 6 weeks after induction of diabetes, 14WD: animals 14 weeks after induction of diabetes, 6WC: control animals 6 weeks after injection of saline, 14WC: control animals 14 weeks after injection of saline, T13: 13th thoracic spinal cord, L1: 1st lumbar spinal cord.

The vertical axis shows the number of cells, and the horizontal axis shows average diameter. Control: •, Diabetes: $\square$. Overlap area of controls with diabetic animals are indicated in gray.

A

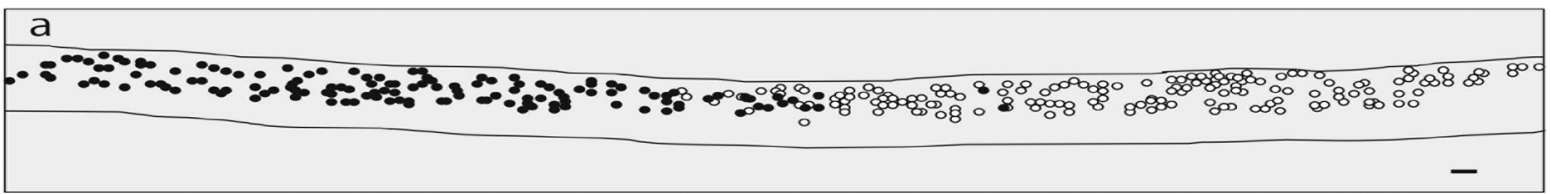

b

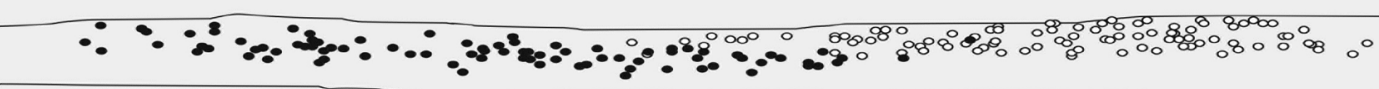

B
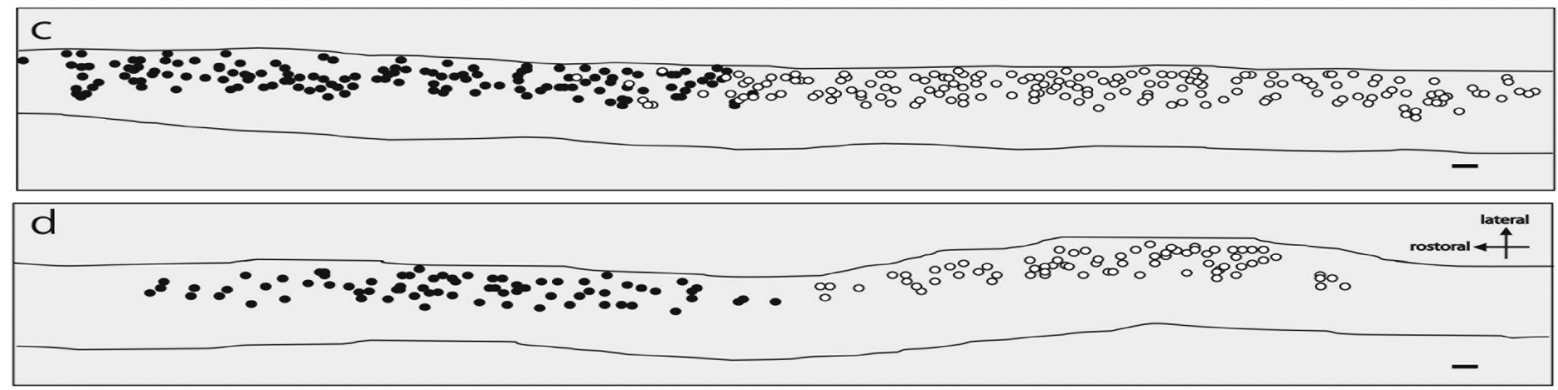

Figure 4: Representative spatial distribution of Abd motoneuronsin horizontal sections.

A: $6 \mathrm{~W}$ animals, a: spatial distribution in a control animal, b: spatial distribution in a diabetic animal. B: $14 \mathrm{~W}$ animals, a: spatial distribution in a control animal, b: spatial distribution in a diabetic animal. $\bullet$ : labeled cell bodies labeled by the T13 nerve, o: labeled cell bodies labeled by the L1 nerve. Bar $=100 \mu \mathrm{m}$. 
Citation: Niwa M, Oshiro N, Muramatsu K, Tamaki T (2018) Streptozotocin-induced Diabetes Causes Crucial Morphological Changes in Abdominal Motoneurons and Muscles of Rats. Int J Phys Ther Rehab 4: 143. doi: https://doi.org/10.15344/2455-7498/2018/143

Page 5 of 8

\begin{tabular}{|c|c|c|c|c|c|c|c|c|c|}
\hline \multirow{3}{*}{$\begin{array}{l}\text { Control } \\
\text { Rat. No }\end{array}$} & \multicolumn{4}{|c|}{ 6WC (327.6-357.5 g, $142.8 \pm 18.6 \mathrm{mg} / \mathrm{dL})$} & \multirow{3}{*}{$\begin{array}{l}\text { Control } \\
\text { Rat. No }\end{array}$} & \multicolumn{4}{|c|}{$14 \mathrm{WC}(379.6-434.0 \mathrm{~g}, 162.4 \pm 24.3 \mathrm{mg} / \mathrm{dL})$} \\
\hline & \multicolumn{2}{|c|}{$\mathrm{T} 13$} & \multicolumn{2}{|c|}{$\mathrm{L} 1$} & & \multicolumn{2}{|c|}{$\mathrm{T} 13$} & \multicolumn{2}{|c|}{ L1 } \\
\hline & Number & $\begin{array}{l}\text { Diameter } \\
(\mu \mathrm{m})\end{array}$ & Number & $\begin{array}{l}\text { Diameter } \\
(\mu \mathrm{m})\end{array}$ & & Number & $\begin{array}{l}\text { Diameter } \\
(\mu \mathrm{m})\end{array}$ & Number & $\begin{array}{l}\text { Diameter } \\
(\mu \mathrm{m})\end{array}$ \\
\hline No. 1 & 262 & $36.8( \pm 8.0)$ & 314 & $37.1( \pm 8.3)$ & No. 6 & 290 & $40.0( \pm 7.9)$ & 250 & $40.5( \pm 7.8)$ \\
\hline No. 2 & 266 & $39.5( \pm 8.2)$ & 308 & $38.6( \pm 8.1)$ & No. 7 & 299 & $38.1( \pm 8.5)$ & 318 & $37.0( \pm 7.5)$ \\
\hline No. 3 & 289 & $41.8( \pm 8.2)$ & 251 & $35.9( \pm 8.0)$ & No. 8 & 260 & $39.9( \pm 8.3)$ & 262 & $35.6( \pm 8.2)$ \\
\hline No. 4 & 298 & $43.6( \pm 8.4)$ & 292 & $39.6( \pm 8.2)$ & No. 9 & 309 & $42.1( \pm 8.4)$ & 293 & $37.3( \pm 8.1)$ \\
\hline No. 5 & 300 & $40.1( \pm 7.9)$ & 275 & $37.6( \pm 7.7)$ & No. 10 & 319 & $41.4( \pm 9.1)$ & 264 & $33.4( \pm 8.4)$ \\
\hline Mean & $283.0( \pm 17.9)$ & $40.4( \pm 2.5)$ & $288.0( \pm 25.6)$ & $37.8( \pm 1.4)$ & Mean & $295.4( \pm 22.6)$ & $40.3( \pm 1.5)$ & $277.4( \pm 27.7)$ & $36.8( \pm 2.6)$ \\
\hline \multirow{3}{*}{$\begin{array}{l}\text { DM } \\
\text { Rat. No }\end{array}$} & \multicolumn{4}{|c|}{ 6WD (175.2-227.0 g, $436.6 \pm 40.7 \mathrm{mg} / \mathrm{dl})$} & \multirow{3}{*}{$\begin{array}{l}\text { DM } \\
\text { Rat. No }\end{array}$} & \multicolumn{4}{|c|}{$14 \mathrm{WD}(140.6-188.0 \mathrm{~g}, 478.0 \pm 51.9 \mathrm{mg} / \mathrm{dl})$} \\
\hline & \multicolumn{2}{|c|}{$\mathrm{T} 13$} & \multicolumn{2}{|c|}{ L1 } & & \multicolumn{2}{|c|}{ T13 } & \multicolumn{2}{|c|}{ L1 } \\
\hline & Number & $\begin{array}{l}\text { Diameter } \\
(\mu \mathrm{m})\end{array}$ & Number & $\begin{array}{l}\text { Diameter } \\
(\mu \mathrm{m})\end{array}$ & & Number & $\begin{array}{l}\text { Diameter } \\
(\mu \mathrm{m})\end{array}$ & Number & $\begin{array}{l}\text { Diameter } \\
(\mu \mathrm{m})\end{array}$ \\
\hline 11 & 173 & $35.5( \pm 5.2)$ & 184 & $32.1( \pm 6.3)$ & 16 & 181 & $30.3( \pm 5.2)$ & 172 & $30.3( \pm 7.3)$ \\
\hline 12 & 174 & $37.7( \pm 6.3)$ & 180 & $36.7( \pm 5.9)$ & 17 & 218 & $33.7( \pm 5.9)$ & 176 & $34.7( \pm 7.0)$ \\
\hline 13 & 161 & $36.0( \pm 8.2)$ & 182 & $33.3( \pm 6.5)$ & 18 & 225 & $34.3( \pm 7.5)$ & 151 & $34.2( \pm 6.5)$ \\
\hline 14 & 304 & $39.6( \pm 7.6)$ & 212 & $35.7( \pm 6.8)$ & 19 & 307 & $37.6( \pm 8.0)$ & 250 & $33.8( \pm 6.7)$ \\
\hline 15 & 293 & $34.9( \pm 7.3)$ & 204 & $35.3( \pm 7.4)$ & 20 & 272 & $34.4( \pm 7.6)$ & 250 & $33.7( \pm 5.9)$ \\
\hline Mean & $221.0( \pm 71.0)$ & $36.7( \pm 1.9)^{*}$ & $192.4( \pm 14.6)^{*}$ & $34.6( \pm 1.9)^{*}$ & Mean & $240.6( \pm 49.2)$ & $34.1( \pm 2.6)$ * & $199.8( \pm 46.8)^{*}$ & $33.3( \pm 1.7)^{*}$ \\
\hline
\end{tabular}

Table 1: Numbers and average diameters of Abd motoneurons.

DM: diabetes mellitus, No: number (Average body weight and average blood glucose concentrations).

Data represented as mean $\pm \mathrm{SD}$ : ${ }^{\star}$ represents $=\mathrm{P}<0.05$ (compared with control animals).

\begin{tabular}{|c|c|c|c|c|c|}
\hline \multicolumn{2}{|c|}{ Control } & \multicolumn{2}{|c|}{$6 \mathrm{WC}(\mathrm{N}=4,334.1-370.7 \mathrm{~g}, 159.3 \pm 32.8 \mathrm{mg} / \mathrm{dL})$} & \multicolumn{2}{|c|}{$14 \mathrm{WC}(\mathrm{N}=6,381.5-468.4 \mathrm{~g}, 171.8 \pm 27.3 \mathrm{mg} / \mathrm{dL})$} \\
\hline & & $\mathrm{T} 13$ & L1 & T13 & L1 \\
\hline EO & \multirow{4}{*}{$\begin{array}{c}(\text { Mean } \pm \text { SD mm }) \\
\text { Layer }\end{array}$} & $0.80( \pm 0.13)$ & $0.73( \pm 0.26)$ & $0.84( \pm 0.17)$ & $0.65( \pm 0.16)$ \\
\hline IO & & $0.88( \pm 0.14)$ & $0.92( \pm 0.19)$ & $0.93( \pm 0.16)$ & $1.26( \pm 0.31)$ \\
\hline TA & & $0.73( \pm 0.08)$ & $0.87( \pm 0.05)$ & $0.82( \pm 0.10)$ & $1.09( \pm 0.25)$ \\
\hline RA & & $2.12( \pm 0.64)$ & 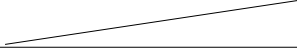 & $2.31( \pm 0.69)$ & $\sim$ \\
\hline \multirow[t]{3}{*}{$\mathrm{TA}$} & Myocytes $\left(\mu \mathrm{m}^{2}\right)$ & $4047.1( \pm 693.3)$ & $4379.5( \pm 1001.7)$ & $4859.5( \pm 780.3)$ & $4904.1( \pm 863.8)$ \\
\hline & Myocytes ( $\mu \mathrm{m}^{2} /$ weight $)$ & $11.2( \pm 1.7)$ & $12.1( \pm 2.5)$ & $11.3( \pm 1.4)$ & $11.4( \pm 1.6)$ \\
\hline & Number of nucleus & $137.5( \pm 14.8)$ & $150.5( \pm 35.3)$ & $132.5( \pm 12.8)$ & $146.5( \pm 29.4)$ \\
\hline \multirow{2}{*}{\multicolumn{2}{|c|}{$\mathrm{DM}$}} & \multicolumn{2}{|c|}{$6 \mathrm{WD}(\mathrm{N}=6,184.1-237.2 \mathrm{~g}, 479.0 \pm 70.5 \mathrm{mg} / \mathrm{dL})$} & \multicolumn{2}{|c|}{$14 \mathrm{WD}(\mathrm{N}=6,140.6-187.6 \mathrm{~g}, 506.8 \pm 62.3 \mathrm{mg} / \mathrm{dL})$} \\
\hline & & T13 & L1 & $\mathrm{T} 13$ & L1 \\
\hline $\mathrm{EO}$ & \multirow{4}{*}{$\begin{array}{c}(\text { Mean } \pm \text { SD mm }) \\
\text { Layer }\end{array}$} & $0.43( \pm 0.08)^{*}$ & $0.38( \pm 0.04)^{*}$ & $0.30( \pm 0.05)^{*}$ & $0.34( \pm 0.13)^{*}$ \\
\hline IO & & $0.52( \pm 0.06)^{*}$ & $0.63( \pm 0.11)^{*}$ & $0.41( \pm 0.07)^{*}$ & $0.62( \pm 0.15)^{*}$ \\
\hline $\mathrm{TA}$ & & $0.57( \pm 0.11)^{*}$ & $0.52( \pm 0.11)^{*}$ & $0.32( \pm 0.08)^{*}$ & $0.30( \pm 0.14)^{*}$ \\
\hline RA & & $1.79( \pm 0.60)$ & 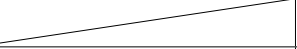 & $1.42( \pm 0.46)^{*}$ & 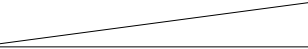 \\
\hline \multirow[t]{3}{*}{$\mathrm{TA}$} & Myocytes $\left(\mu \mathrm{m}^{2}\right)$ & $2003.8( \pm 368.2)^{*}$ & $1866.8( \pm 483.6)^{*}$ & $1047.3( \pm 296.3)^{*}$ & $990.0( \pm 343.6)^{*}$ \\
\hline & Myocytes ( $\mu \mathrm{m}^{2} /$ weight) & $9.3( \pm 0.7)$ & $8.6( \pm 1.3)^{*}$ & $6.4( \pm 1.5)^{*}$ & $6.0( \pm 1.7)^{*}$ \\
\hline & Number of nucleus & $118.7( \pm 13.2)$ & $119.0( \pm 8.5)$ & $126.7( \pm 26.1)$ & $131.0( \pm 24.0)$ \\
\hline
\end{tabular}

Table 2: Thicknesses and Myocytes and Nucleus number of type the muscle in each area.

EO: external oblique, IO: internal oblique; TA: transversus abdominis, RA: rectus abdominis, DM: diabetes mellitus (Number of rats, average body weight and average blood glucose concentrations).

Data represented as mean $\pm \mathrm{SD}:{ }^{\star}$ represents $=\mathrm{P}<0.05$ (compared with control animals). 
A
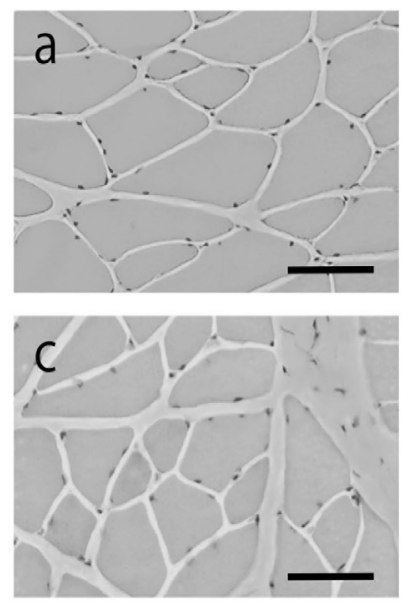
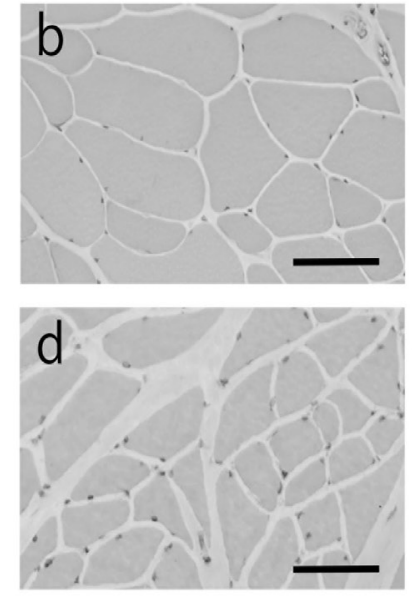

B
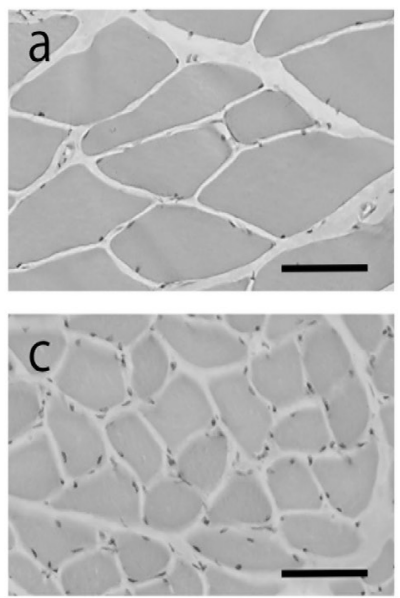
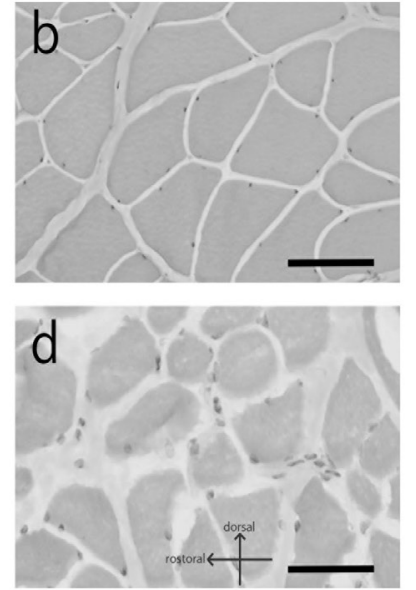

Figure 5: Representative transverse sections of TA muscle.

A: 6WC and 6WD, a: transverse sections of T13 in a control animal, b: transverse sections of L1 in a control animal, c: transverse sections of T13 in a diabetic animal, d: transverse sections of L1 in a diabetic animal. B: 14WC and 14WD, a: transverse sections of T13 in a control animal, b: transverse sections of L1 in a control animal, c: transverse sections of T13 in a diabetic animal, d: transverse sections of L1 in a diabetic animal. $6 \mathrm{WD}$ : animals 6 weeks after induction of diabetes, 14WD: animals 14 weeks after induction of diabetic, $6 \mathrm{WC}$ : control animals 6 weeks after injection of saline, $14 \mathrm{WC}$ : control animals 14 weeks after injection of saline, T13: 13th thoracic spinal cord, L1: first lumbar spinal cord. Bar=100 $\mu \mathrm{m}$.

\section{Discussion}

\section{Abd Motoneurons}

In a previous paper, we discussed the possibility that decreased labelling of motoneuronsmay not be caused by technical problems with retrograde labeling[7, 19-22]. In this study, we revealed an aspect of diabetes pathology in Abd motoneurons. We previously found that both size and number of presumed gamma motoneurons were reduced (22 weeks after STZ injection) in rats [7] but later reported that large (presumed alpha) and small gamma motoneurons of the MG nuclei had smaller cross-sectional areas (12 weeks after STZ injection) and were fewer in number (12 and 24 weeks after STZ injection)[8]. In this study, however, we revealed that only 6 weeks of diabetes induced the loss of Abd motoneurons. Since there is no data of hind-limb motoneurons after 6 weeks following induction of diabetes, it cannot be compared, but Abd motoneurons are considered to be similarly damaged by hyperglycemia.

As shown in Figure 3, size of Abd motoneurons showed unimodal distribution. This was differenced from hindlimb motoneurons whose size showed bi-modal distributions, in that small groups corresponded to gamma motoneurons and large groups to alpha motoneurons $[8$, 10]. However, this difference does not mean that Abd motoneurons do not have gamma motoneurons. Because it was previously reported size distribution of Abd motor fibers in peripheral nerves showed a bi-modal distribution and it is very likely that the large motor fibers corresponded to alpha motor fibers and the small motor fibers corresponded to gamma motor fibers, although size distribution of Abd cell bodies showed uni-modal [10]. It also known when positive pressure was imposed at the end-expiratory line, Abd alpha and gamma motor fibers exhibited the expiratory activity, in response to the positive air pressure [17]. Therefore, anatomical and physiological data suggest that Abd muscles were innervated by alpha and gamma motoneurons.
In this study, the number and mean size of cell bodies decreased in Abd motoneurons in the diabetic group. Additionally, size distribution of Abd motoneurons showed a decrease of the number of larger motoneurons (Figure 3). At first grace, the main component of these alterations seems to be occurred by a loss of larger alpha motoneurons. However, our previous report indicated that the diabetes predominantly induces loss of gamma motoneurons innervating MG muscle spindles [7]. Alteration of size distribution may cause by shrinkage of the cell bodies of larger alpha motoneurons and loss of smaller gamma motoneurons.

\section{Abd Muscles}

There was a clear decrease in the muscle thicknesses in the diabetic group. The thickness of each muscle was almost halvedbetween that of $14 \mathrm{WC}$ and $14 \mathrm{WD}$ animals. Therefore, the functional decline in Abd muscles will appear to be remarkable with diabetes. The sizes of myocytes in TA muscle decreased in the diabetic animals. The thinning of Abd muscles might have little or no relationship to decrease of the number of motoneurons and there were few angulated fibers in the diabetic animals, which were characteristic of neurogenic muscle atrophy. Compared to a decrease in the number of motoneurons, thinning of the muscle was remarkable (Abd muscles which were innervated by motoneurons in the T13 segment decreased in thickness without significant loss of motoneurons). This discrepancy of the number of Abd motoneurons and atrophy of Abd muscles suggests that muscle thinning might be caused by lack of nutritional supply due to peripheral vascular injury, etc. It is known that if denervation progresses slowly, muscle will not show typical degeneration atrophy because preserved motoneurons are given time to re-innervate muscle fibers. It also suggests that loss of Abd motoneurons might occur on gamma motoneurons which innervate intra-fusal fiber of muscle spindle. Therefore, it was not related to thinning of the muscle. 
Citation: Niwa M, Oshiro N, Muramatsu K, Tamaki T (2018) Streptozotocin-induced Diabetes Causes Crucial Morphological Changes in Abdominal Motoneurons and Muscles of Rats. Int J Phys Ther Rehab 4: 143. doi: https://doi.org/10.15344/2455-7498/2018/143

Page 7 of 8

It might seem to be natural to conclude thatdiabetes targets the gamma motoneurons innervating the distal muscles of the hindlimbby which MG gamma motoneurons are injured, while biceps femolis motoneurons are preserved [8]. This might reflect the characteristic of DN featuring length-dependent peripheral nerve disorders referred to as "stocking and glove" signs and symptoms. However, it is unclear why Abd muscles, which are not innervated by long peripheral nerves,are damaged severely. A study of rat leg muscles indicated that fast-twitch skeletal muscle fibers are more dependent on insulin for maintenance of their normal metabolic and morphological characteristics than slow-twitch fibers [23], and that fast-twitch muscles undergo profound wasting and decreased strength [24]. Furthermore, the isomyosins of slow-twitch oxidative myofibers are more resistant to hormonal and metabolic disorders during diabetes than the isomyosins of fast-twitch fibers [25]. Abd muscles of rats might have a large number of fast-twitch fibers, or Abd muscles might have been severely injured in the diabetic group due to the basic structural differencesfrom lower limbs.

Patients with type 1 diabetes mellitus have been showed to have a significantly lower than normal total lung capacity, residual volume, and forced vital capacity [26]. This suggests that a restrictive type of lung disease can be caused by an intrinsic lung-tissue derangement as well as pulmonary microangiopathy [26]. Moreover, some of these causesmay result in dysfunction of Abd muscles because they contribute to increases in intra-abdominal pressure [18].

Loss of Abd motoneurons and decrease in Abd muscle thickness were observed after induction of diabetes by streptozotocin. Therefore, Abd muscular disorders would be related to a wide range of disorders such as those involved with expiratory, defecation function, and trunk movement. We would like to examine the mechanisms of the disorders of motoneurons and muscles by using immunohistochemical and electrophysiological techniques in the future.

\section{Conclusions}

This study investigated morphological alterations in Abd motoneurons and muscles of experimental type I diabetic rats. The number and mean size of cell bodies decreased in Abd motoneurons in the diabetic group. There was a clear decrease in muscle thickness and in the cross-sectional area of the myocytes in the diabetic group. We suggest that the hyperglycemia could induce the reduction of number and size of Abd motoneurons and the atrophy of Abd muscles. Those were observed at 6 and 14 weeks after induction of diabetes by streptozotocin. Therefore, Abd muscular disorders caused by the hyperglycemia would relate to a wide range of disorders such as those involved with expiratory, defecation function, and trunk movement.

\section{Acknowledgement}

We would like to thank Dr. Seiichi Sasaki for his advice. We would also like to thank Editage (www.editage.jp) for English language editing.

\section{Competing Interests}

The authors declare no potential conflicts of interest with respect to the research, authorship, and/or publication of this article.

\section{Author Contributions}

NO performed all the described experiments.

NO and MN designed the study, analyzed, and evaluated the data and authored the manuscript.

All co-authors participated in data collection and analysis and have read and approved the final manuscript.

\section{Funding}

This study was supported by KAKENHI (16K01468), Japan.

\section{References}

1. Andersen H (2012) Motor dysfunction in diabetes. Diabetes Metab Res Rev 28: 89-92.

2. Dobretsov M, Romanovsky D, Stimers JR (2007) Early diabetic neuropathy: triggers and mechanisms. World J Gastroenterol 13: 175-191.

3. Dyck PJ, Giannini C (1996) Pathologic alterations in the diabetic neuropathies of humans: a review. J Neuropathol Exp Neurol 55: 1181-1193.

4. Abadi L, Salahzadeh Z, Rezaei M, Oskouei AE, Azghani MR, et al. (2017) Hip joint torques in type II diabetes with and without neuropathy. Hong Kong Physiotherapy J 37: 27-33.

5. Ijzerman TH, Schaper NC, Melai T, Meijer K, Willems PJB, et al. (2012) Lower extremity muscle strength is reduced in people with type 2 diabetes, with and without polyneuropathy, and is associated with impaired mobility and reduced quality of life. Diabetes Res and Clin Pract 95: 345-351.

6. Almurdhi MM, Reeves ND, Bowling FL, Boulton AJM, Jeziorska $M$, et al. (2016) Reduced lower-limb muscle strength and volume in patients with type 2 diabetes in relation to neuropathy, intramuscular fat, and vitamin D levels. Diabetes Care 39: 441-447.

7. Kishi M, Tanabe J, Schmelzer JD, Low PA (2002) Morphometry of dorsal root ganglion in chronic experimental diabetic neuropathy. Diabetes 51: 819-824.

8. Zochodne DW, Ramji N, Toth C (2008) Neuronal targeting in diabetes mellitus: astory of sensory neurons and motor neurons. Neuroscientist 14 311-318.

9. Muramatsu K, Niwa M, Nagai M, Kamimura T, Sasaki S-I, et al. (2012) The size of motoneurons of the gastrocnemius muscle in rats with diabetes. Neurosci Lett 531: 109-113.

10. Muramatsu K, Niwa M, Tamaki T, Ikutomo M, Masu Y, et al. (2017) Effect of streptozotocin-induced diabetes on motoneurons andmuscle spindles in rats. NeurosciRes 115: 21-28.

11. Hijikata T, Wakisaka H, Yohro T (1992) Architectural design, fiber-type composition, and innervation of the rat rectus abdominis muscle. Anat Rec 234: $500-512$

12. Niwa M, Nakayama K, Sasaki SI (2008) Morphological study of external oblique motor nerves and nuclei in cats. Anat Sci Int 83: 17-25.

13. Floyd WF, Walls EW (1953) Electromyography of the sphincter ani externus in man. J Physiol 122: 599-609.

14. Waters RL, Morris JM (1972) Electrical activity of muscles of the trunk during walking. J Ana 111: 191-199.

15. Goldman JM, Lehr RP, Millar AB, Silver JR (1987) An electromyographic study of the abdominal muscles during postural and respiratory manoeuvres. J Neurol Neurosurg Psychiatry 50: 866-869.

16. Miller AD, Tan LK, Suzuki I (1987) Control of abdominal and expiratory intercostal muscle activity during vomiting: role of ventral respiratory group expiratory neurons. J Neurophysiol 57: 1854-1866.

17. Bishop B (1964) Reflex control of abdominal muscles during positive pressure breathing. J Appl Physiol 19: 224-232. 
Citation: Niwa M, Oshiro N, Muramatsu K, Tamaki T (2018) Streptozotocin-induced Diabetes Causes Crucial Morphological Changes in Abdominal Motoneurons and Muscles of Rats. Int J Phys Ther Rehab 4: 143. doi: https://doi.org/10.15344/2455-7498/2018/143

18. Miller AD (1987) Localization of motoneurons innervating individual abdominal muscles of the cat. J Comp Neuro 256: 600-606.

19. Russel JA, Bishop BP, Hyatt RE (1987) Discharge of abdominal muscle a and g motoneurons during expiratory loading in cats. Exp Neurol 97: 179-192.

20. Niwa M, Muramatsu K, Sasaki SI (2015) Discharge patterns of abdominal and pudendal nerves during induced defecation in anesthetized cats. $J$ Physiol Sci 65: 223-231.

21. Fritzsch B (1993) Fast axonal diffusion of 3000 molecular weight dextran amines. J Neurosci Methods 50: 95-103.

22. Arvidsson J, Aldskogius H (1982) Effect of repeated hypoglossal nerve lesions on the number of neurons in the hypoglossal nucleus of adult rats. Exp Neurol 75: 520-524

23. Gu Y, Spasic Z, Wu W (1997) The effects of remaining axons on motoneuron survival and NOS expression following axotomy in the adult rat. Dev Neurosci 19: 255-259.

24. Noven SV, Wallace N, Muccio D, Turtz A, Pinter MJ, et al. (1993) Adult spinal motoneurons remain viable despite prolonged absence of functional synaptic contact with muscle. Exp Neurol 123: 147-156.

25. Armstrong RB, Gollnick PD, Ianuzzo CD (1975) Histochemical properties of skeletal muscle fibers in streptozotocin-diabetic rats. Cell Tiss Res 162:387394.

26. Cotter MI, Cameron NE, Lean DR, Robertson S (1989) Effects of long-term streptozotocin diabetes on the contractile and histochemical properties of rat muscles. J Exp Physiol 74: 65-74.

27. Rutschmann M, Dahlmann B, Reinauer H (1984) Loss of fast-twitch isomyosins in skeletal muscles of the diabetic rat. Biochem J 221: 645-650.

28. Kamiya H, Zhang W, Sima AAF (2009) Dynamic changes of neuroskeletal proteins in DRGs underlie impaired axonal maturation and progressive axonal degeneration in type 1 diabetes. Exp Diabetes Res 2009: 14

29. Stubbe B, Schipf S, Schäper C, Felix SB, Steveling A, et al. (2017) The influence of type 1 diabetes mellitus on pulmonary function and exercise capacity - results from the Study of Health in Pomerania (SHIP). Exp Clin Endocrinol Diabetes 125: 64-69. 